\title{
Erratum to: Recurrent Linear Operators
}

\author{
George Costakis • Antonios Manoussos • \\ Ioannis Parissis
}

Published online: 25 January 2015

(C) Springer Basel 2015

\section{Erratum to: Complex Anal. Oper. Theory (2014) 8:1601-1643 DOI 10.1007/s11785-013-0348-9}

Unfortunately, the Communication Editor name was incorrectly published in the original publication of the above mentioned article. The correct name is given below:

Communicated by Simeon Reich

The online version of the original article can be found under doi:10.1007/s11785-013-0348-9.

G. Costakis

Department of Mathematics, University of Crete, Knossos Avenue,

71409 Heraklion, Crete, Greece

e-mail: costakis@math.uoc.gr

URL http://www.math.uoc.gr:1080/Members/costakis

\section{A. Manoussos}

Fakultät für Mathematik, SFB 701, Universität Bielefeld, Postfach 100131,

33501 Bielefeld, Germany

e-mail: amanouss@math.uni-bielefeld.de

URL http://www.math.uni-bielefeld.de/ amanouss

I. Parissis $(\varangle)$

Department of Mathematics, Aalto University, P. O. Box 11100, 00076 Aalto, Finland

e-mail: ioannis.parissis@gmail.com

URL http://www.math.aalto.fi/ parissi 1 